\section{O ATENDIMENTO PSICOLÓGICO AO ADOLESCENTE E $O$ CARÁTER TERAPÊUTICO DA ORIENTAÇÃO DE PAIS: ESTUDO DE CASO EM TERAPIA SISTÊMICA INDIVIDUAL}

\author{
PSYCHOLOGICAL INTERVENTION OF THE ADOLESCENT AND THE \\ THERAPEUTIC CHARACTER OF THE ORIENTATION OF PARENTS: A CASE \\ STUDY IN INDIVIDUAL SYSTEMIC THERAPY
}

\begin{abstract}
This paper is a case study about the individual systemic therapy with one teenager and her parents. It's objective is to show to show the importance of individual systemic therapy with children and adolescents also including the family in the orientation of parents. Metaphors, circular questions and therapeutic games were used in individual sessions and sessions of orientation of parents. Individual sessions and parenting sessions were focused on the dynamical relationships of the family group and their impact in adolescent development, emphasizing the complexity, instability and intersubjectivity that exist in the parents and children relationship.
\end{abstract}

KEYWORDS: Psychotherapy of Adolescent; Orientation of Parents; Individual Systemic Therapy.
ETIENE OLIVEIRA SILVA DE MACEDO ${ }^{1}$

ANALICE DE SOUSA ARRUDA VINHAL CARVALHO²

${ }^{1}$ Instituto de Educação em Psicologia (Goiânia-GO) Universidade Paulista (Campus Goiânia)

${ }^{2}$ Instituto de Educação em Psicologia (Goiânia-GO)

Pontifícia Universidade Católica de Goiás Universidade Paulista (Campus Goiânia)

\title{
INTRODUÇÃO
}

A família contemporânea passa por modificações que a desafiam na criação de novos arranjos e modos de existência. A velocidade das transformações sociais, a instabilidade econômica, as mudanças da atualidade requerem, de uma ou outra forma, criatividade e flexibilidade para adaptação a esses novos modos de vida, tão diferentes daqueles vivenciados nos séculos anteriores (Berthoud, 2003; Walsh, 2016).

Os terapeutas contemporâneos têm abandonado o foco nas limitações em direção a um paradigma orientado às competências e aos pontos fortes das famílias. Todas as abordagens de Terapia Familiar, em que pese as diferentes ênfases
Recebido em: 13/09/2018 Aprovado em: 04/06/2019 
teóricas, compartilham da ideia de que os componentes familiares são dinâmicos e interativos. Sejam padrões estruturais, formas de comunicação ou produção de significados, os terapeutas familiares orientam-se do déficit para o crescimento em busca de reconhecer e ampliar o potencial construtivo da família nessa reinvenção da vida (Walsh, 2016).

Este artigo apresenta um estudo de caso que mostra a contribuição da terapia sistêmica com foco no atendimento ao adolescente e sua família. Os eixos teóricos desse artigo articulam os pressupostos do pensamento sistêmico (Vasconcelos, 2010) com a terapia individual de orientação sistêmica (Boscolo \& Bertrando, 2013).

As reflexões foram construídas a partir do atendimento psicoterapêutico de uma adolescente e seus pais. O recorte deste trabalho será a tarefa da adolescência e a parentalidade, a partir do atendimento psicoterapêutico de uma adolescente e sua família nesse momento do ciclo vital. Trabalhos voltados ao atendimento infantil são mais comuns e têm um amplo escopo de publicações e métodos sistematizados. Estudos clínicos com foco no atendimento do adolescente ainda não têm a mesma robustez, principalmente na perspectiva do atendimento sistêmico. Essa é a maior contribuição pretendida com este artigo.

O objetivo é trazer alguns apontamentos sobre a adolescência no desenvolvimento do ciclo vital familiar, a partir de um estudo de caso de um processo de atendimento clínico realizado com uma adolescente. Serão apresentadas vinhetas ilustrativas agregadas às reflexões desenvolvidas ao longo do processo terapêutico realizado.

O pensamento sistêmico contribui com a elucidação do fenômeno psicológico a partir de pressupostos como a complexidade, a instabilidade e a intersubjetividade. Por complexidade se compreende a capacidade auto-organizadora do sistema em que o todo é indissociável da parte, ao mesmo tempo em que, separadamente, a parte traz aspectos constitutivos do todo, sem, contudo, apresentá-lo por completo. A instabilidade faz referência ao caráter dinâmico do conhecimento, não há verdades a priori, pois o mundo é movimento e imprevisibilidade. E o pressuposto da intersubjetividade entende que não há neutralidade entre observador e o fenômeno observado (Vasconcelos, 2010).

Assim, para a teoria sistêmica, uma queixa comparece como tal em função de sua própria relação na constituição do sistema familiar. O objetivo do terapeuta sistêmico é interagir com os familiares, na criação conjunta de hipóteses e desenvolvimento de recursos a partir das interações no próprio sistema familiar, em lugar da intervenção diretamente voltada à remissão de sintomas ou modificação de comportamentos-alvo.

Frente às queixas e conflitos geradores de sofrimento, a abordagem à família é cuidadosa para não estabelecer objetivos terapêuticos irrealistas, baseados em padrões clínicos e culturais a partir do binômio saúde-doença, sem considerar o próprio modo de vida de cada família. Cada sistema tem um funcionamento que lhe é peculiar e a normalidade ou disfunção só tem sentido no contexto específico dos subsistemas envolvidos (Walsh, 2016).

Por sistema compreende-se a organização familiar e sua transformação, a partir da regulação dos comportamentos de seus membros. A família é um sistema que possui subsistemas como o conjugal, parental e fraternal, que funcionam a partir de padrões transacionais e geracionais necessários 
à sobrevivência do grupo. Também é um sistema emocional transversal à dimensão temporal ou geracional, podendo influenciar além da terceira ou quarta geração (Carter \& McGoldrick, 1995a; Nichols \& Schwartz, 2007).

Assim, compreender a dinâmica das relações entre os membros de uma família dentro de sua estrutura é mais importante do que se ater ao seu formato propriamente dito. São os laços relacionais que organizam as pessoas dentro de um grupo familiar e as mantêm de alguma forma vinculadas. E essas relações são insubstituíveis. Famílias se arranjam e rearranjam em formatos diferentes. Mas é a qualidade da relação construída quando os subsistemas interagem que as habilita para criarem seus próprios caminhos, serem flexíveis e resilientes (McGoldrick \& Shibusawa, 2016; Walsh, 2016).

A partir da reflexão desses autores, compreendemos que prover espaços relacionais de pertencimento e aceitação entre adolescentes e seus pais em meio aos conflitos geracionais é um dos, se não o maior desafio de terapeutas infantojuvenis sistêmicos.

Para compreender esses conflitos, a noção de ciclo vital familiar é fundamental. A estrutura clássica do ciclo vital familiar compreende oito estágios que são articulados aos eventos transicionais que a família vivencia: casamento, nascimento de filhos, educação de filhos durante a primeira infância, educação de filhos durante a pré-escola, educação de filhos durante a adolescência, o preparo e saída do lar, o estágio do ninho vazio até o último estágio, com a aposentadoria e falecimento de um dos cônjuges.

Em cada estágio existem tarefas esperadas que fazem parte do processo normativo do desenvolvimento familiar, que podem ser realizadas com maior ou menor estresse, dependendo de inúmeros fatores (Carter \& McGoldrick, 1995a).

Segundo as autoras, as experiências familiares ao longo do tempo são marcadas por fluxos verticais e horizontais. Por fluxos verticais entende-se os padrões de relacionamento e funcionamento transmitidos ao longo do tempo, como tabus, crenças, mitos, lealdades. Por fluxos horizontais compreende-se aqueles estressores previsíveis e imprevisíveis ao longo do tempo que suscitam ansiedade e demandam remanejamentos ao sistema familiar.

A adolescência, por exemplo, é um estressor horizontal, normativo, que qualquer família com filhos enfrenta. Mas o grau de dificuldade da relação entre pais e filhos durante esse estágio depende de como convergem os estresses verticais e horizontais em cada família. Ou seja, depende da confluência dos mitos, valores e legados com a vivência familiar sobre esse estágio. Assim, para determinadas famílias, a adolescência pode ser vivenciada com maior sofrimento e, para outras, pode ser um estágio promissor para o crescimento coletivo e individual de cada membro (Carter \& McGoldrick, 1995a).

De acordo com o desenho formal do ciclo de vida familiar, podemos dizer que primeiro os casais se juntam e formam a família, depois se preparam para ter filhos, aprendem a cuidar desses filhos e, em seguida, sentem que desaprendem, quando a adolescência chega. Depois de crescidos, alguns conflitos resolvidos, outros não, os filhos saem de casa. E o casal tem novas tarefas e o desafio de seguir como casal e se preparar para a velhice e finitude (Carter \& McGoldrick, 1995a).

A ideia de transição como uma passagem decisiva em momentos-chave do ciclo de vida é bem aceita 
1 Embora o marco etário civil da adolescência seja os 12 anos de idade, esse trabalho adota como adolescência a faixa etária compreendida entre 10 a 19 anos, preconizada pela Organização Mundial de Saúde (WHO, 2014), a qual inclui a chamada puberdade, ou pré-adolescência, que compreende a faixa etária entre 10 e 12 anos de idade. por estudos psicológicos e estudos de família. Desde os estudos psicanalíticos ericksonianos e freudianos, essa metáfora busca compreender as tarefas e desequilíbrios inerentes aos momentos vividos pelo sujeito durante a vida (Cowan \& Cowan, 2016).

Ao nascer o primeiro filho, se inicia a transição para a parentalidade. Ao fim da idade adulta, dá-se a transição para velhice. A adolescência ${ }^{1}$ é vista como uma transição para a vida adulta. Um momento em que confluem demandas biopsicossociais para a criança em transformação e também para sua família. Podemos então considerar a pré-adolescência como uma transição para a adolescência?

A pré-adolescência, ou, como amplamente aceito, adolescência precoce, compreende o período que vai dos 11 aos 13 anos. É nessa faixa etária que ocorrem mais intensamente as mudanças cognitivas decorrentes da puberdade, com ressonância na vida psicológica e social. Entre 14 e 16 anos, o adolescente desenvolve um interesse maior pela sexualidade, pelo relacionamento com pares e um senso moral. Esse período é chamado de adolescência média, ou propriamente dita. E por fim, durante a adolescência tardia, de 17 a 19 anos, acontece a consolidação da identidade e autonomia em relação ao grupo familiar, marcando esse ciclo de desenvolvimento (Micucci, 2009).

Entretanto, nossa experiência clínica e de pesquisa mostra que o período que vai dos 11 aos 13 anos comparece como infância, ou pré-adolescência, no discurso social e familiar. Essa dificuldade em reconhecer e legitimar o momento inicial da adolescência acentua o estranhamento e o sentimento de não pertencer, que é vivenciado durante a adolescência. Podemos inferir que essas concepções refletem o que denominamos o "não-lugar" que é vivido pelos adolescentes em nossa sociedade. Ora criança ora adolescente, o pré-adolescente se torna invisível quando, na realidade, está vivenciando intensamente as transformações dos anos iniciais da adolescência (Macedo, 2010; Macedo, 2018; Macedo \& Conceição, 2015).

A concepção negativa de adolescência em termos de instabilidade, da transitoriedade, do não ser e seus processos naturalizados de socialização (a ideia de crise da adolescência) contribui para uma generalização indiscriminada e a invisibilidade das necessidades específicas desse grupo etário. Quando visíveis, enfatiza-se mais o risco do que a oportunidade para a prevenção ou desenvolvimento recursivo do adolescente nesse processo (Macedo, 2010; Macedo \& Conceição, 2015).

A cultura ocidental concebe esse período como uma transição normativa. Ou seja, novos arranjos psicológicos são construídos e provocam profundas mudanças nas definições de identidade e papéis. Mais do que uma mudança, a transição provoca transformações que vão repercutir profundamente tanto na criança quanto nos sistemas dos quais ela participa (Cowan \& Cowan, 2016).

Muda-se do status de criança para adolescente; muda-se o status da função parental exercida pelas famílias. Entretanto, essas transformações acontecem num campo de tensão onde percebemos resistência e dificuldade de negociações, principalmente por parte dos adultos, que necessitam outras estratégias parentais. Muitos conflitos acontecem devido à cristalização no imaginário dos pais a respeito de seus filhos e sua incapacidade de lidar com as demandas que o adolescente traz. Torna-se necessário 
ampliar fronteiras: permitir o afastamento e aproximação do adolescente, conforme o grau de dificuldade para manejar as situações que vivencia (Carter \& McGoldrick, 1995b).

$\mathrm{O}$ adolescente tem a tarefa de se aventurar em decisões próprias, fazer escolhas que podem ser diferentes das escolhas dos pais. Algumas vezes esse movimento desencadeia conflitos emocionais e o afastamento de pessoas até então tidas como fundamentais. Os pais, sentindo-se "rebaixados" ao segundo plano, têm a tarefa de permitir essa mudança, sem que isso implique um abandono ou ausência na vida dos filhos (Macedo, 2018).

Essa é uma das maiores dificuldades do sistema familiar: permitir uma maior separação sem o rompimento de relações e vínculos, manejando os estressores e riscos de perda da boa convivência familiar. Não há dúvida de que esse período afeta os pais, os cônjuges, irmãos e todo o restante do sistema familiar. O quanto esse sistema será ou não afetado vai depender deles mesmos a priori (Guimarães \& Costa, 2003).

Abordar a família na perspectiva relacional sistêmica não prescinde da importância de compreendermos o comportamento individual em seu ciclo evolutivo. Para isso, Andolfi (1984) destaca a necessidade de diferenciação como constitutiva do desenvolvimento individual dentro do ciclo familiar. O indivíduo integra um grupo familiar coeso o bastante para que ele possa gradualmente se diferenciar em busca da autonomia e independência. Essa individuação não leva ao rompimento dos vínculos familiares, mas sim a uma reconfiguração do sistema com novas funções e tarefas.

A capacidade de mudar, se deslocar, participar, separar e juntar permite a emergência de funções únicas, além da aquisição de outras necessárias ao momento do ciclo vital familiar. A organização-desorganização que é vivida pela família como instabilidade, incerteza marca a passagem para um novo equilíbrio funcional. E quanto mais a família suporta esse processo, maior será a capacidade de diferenciação do indivíduo, em termos da aquisição de habilidades para as reconfigurações do sistema familiar e para seu crescimento pessoal (Andolfi, 1984).

A família precisa desenvolver a capacidade de tolerar e resolver os conflitos, sem permitir o aniquilamento das individualidades. Adolescentes que vivem em ambientes onde se permite contradições e peculiaridades tendem a construir um senso de si e a capacidade para relações de intimidade, mais do que aqueles que vivem em ambientes rígidos e punitivos (Kobac \& Mandelbaum, 2003).

Ou seja, se os pais podem permanecer amando durante o processo de individuação, os adolescentes mantêm o senso de sentirem-se amáveis ao alcançar a individualidade. Quando podem expressar raiva e tristeza em relação aos pais, podem se desenvolver de forma mais autônoma, sem o enfraquecimento dos vínculos entre pais e filhos.

Assim como na infância, os adolescentes precisam ser afirmados por seus cuidadores em três dimensões: que será possível e permitida uma comunicação aberta com seus pais; que eles são acessíveis; que fornecerão apoio e presença quando necessário. A diminuição de contatos físicos, de que os pais se queixam, não é necessariamente diminuição do afeto, mas se passa a uma negociação na expressão dos sentimentos, em que a relação entre pais e filhos precisa estimular a autonomia dos adolescentes (Diamond \& Stern, 2003). 
$\mathrm{Ou}$ seja, diferentemente do que se imagina, a presença de adultos de referência é fundamental para o suporte psicológico do adolescente nessa vivência contraditória e fluida da adolescência. Afirmar sua autonomia sem a represália da crítica, ameaças e rejeição, promover diálogo, acolher dúvidas, medos, tolerar as mudanças de gostos, de humor, tudo isso confere ao adolescente confiança para crescer (Lopes Oliveira, 2006, Macedo \& Conceição, 2015).

Em pesquisa de mestrado, uma das autoras desse artigo também constatou que os adolescentes aspiram a relações de confiança e intimidade com seus pais. Eles esperam da família presença e o entendimento de que o momento da adolescência é estranho não somente para os pais, mas também para eles (Macedo, 2010).

Nesse sentido, podemos afirmar que a relação entre pais e filhos durante a adolescência tanto pode ser fator de risco como de proteção para a saúde mental desse grupo etário. Apesar do aparente afastamento dos adolescentes em relação à família, ainda assim eles precisam de proximidade e constância. Os pais têm a tarefa de redefinir os limites de sua autoridade, mantendo, ao mesmo tempo, laços de confiança e comunicação aberta. E os adolescentes têm o desafio de aprender a circular entre a autonomia e a dependência numa dialética afastamento-aproximação.

Adolescentes que vivem em famílias onde não são permitidos seus questionamentos e conflitos, ou seja, que não têm relações seguras nas famílias, correm mais risco de desenvolverem problemas de comportamento como uso abusivo de substâncias, transtornos psicológicos e gravidez precoce. (McGoldrick \& Shibusawa, 2016).
Também entendemos por relações seguras aquelas em que entre os integrantes dos grupos é permitida expressão de diferenças. Kobac e Mandelbaum (2003) sugerem que as conversações entre famílias em que os adolescentes possam manifestar livremente seus sentimentos em relação às experiências vividas colaboram para a manutenção de relações de apego mais seguras e vinculações saudáveis.

A família tem a tarefa de se abrir para novos olhares e permitir que o adolescente faça experimentações diferentes daquelas que eram delegadas durante a infância. A família que apresenta dificuldade de permitir essa flexibilidade está, provavelmente, congelada na ideia anterior de seus filhos. Havendo esta rigidez, o conflito se torna inevitável e o distanciamento pode perdurar ao longo do desenvolvimento do adolescente com prejuízos para todos (McGoldrick \& Shibusawa, 2016).

O maior desafio para os pais durante a adolescência é o exercício de sua função parental. Se antes os pais participavam com voz ativa e a ideia de controle sobre a vida e rotina dos filhos, agora eles sentem que os filhos estão se esvaindo. Faltam estratégias para manejar conflitos e, dependendo das pessoas envolvidas na trama relacional, há um nítido distanciamento físico e relacional. Concebemos como função parental a concretização da parentalidade.

Berthoud (2003) define como parentalidade a experiência relacional envolvida na interação entre pais e filhos, com profundo significado psicológico, num constante processo de mudança que perpassa todo o ciclo vital. Mais do que práticas parentais moldadas por características individuais, envolve o contexto sociocultural e as articulações possíveis entre os sujeitos, entre pais e filhos. 
Segundo Berthoud (2003), numa perspectiva sistêmica, a parentalidade pode ser definida em duas vertentes: parentalidade de primeira ordem e parentalidade de segunda ordem. Uma estaria relacionada às práticas e atos propriamente ditos que visam à correção de comportamentos indesejáveis e atos educativos para com os filhos. Outra, a parentalidade secundária, estaria relacionada aos significados e implicações dos próprios pais em tais práticas.

Numa perspectiva sistêmica, importa mais compreender a influência mútua que pais e filhos exercem sobre si, do que apresentar modelos padronizados de conduta do que seja certo ou errado na educação parental. Ao considerar pais e filhos como sistemas em interação, a noção de causa e efeito é ampliada para a compreensão dos múltiplos elementos que influenciam a parentalidade (Micucci, 2009).

Nesse sentido, para compreender sistemicamente a parentalidade em famílias com adolescentes é importante considerar: o contexto interacional onde ocorre o comportamento e a causalidade circular nessa interação; os processos reflexivos em detrimento de "como fazer", ampliando assim as possibilidades de mudança do comportamento parental (Berthoud, 2003).

Outro elemento que influencia a prática educativa é a coparentalidade. Esse termo se refere ao compartilhamento das responsabilidades educativas entre pais e mães e como a organização das funções parentais podem ser complementares ou antagônicas. Embora sofra o impacto dos aspectos psicossociais e econômicos de cada sistema familiar, a coparentalidade não contempla aspectos da vida conjugal, sexual, financeira ou legal que não inclua a educação de filhos. Por isso, em cada família, a coparentalida- de tem características contingenciais e específicas (Beiras \& Souza, 2015; Feinberg, 2003; Margolin, Gordis, \& John, 2001).

Fatores socioeconômicos, crenças e valores culturais influenciam como o casal exerce as práticas educativas e como pai e mãe (no caso da família biparental clássica) vivenciam o exercício de seu papel parental. Atualmente, a participação paterna no exercício coparental está além da função de provisão e subsistência. Participar da rotina diária de cuidado com os filhos desde os primeiros anos do nascimento facilita a criação de laços afetivos protetivos para o desenvolvimento saudável (Beiras \& Souza, 2015).

\section{O ATENDIMENTO SISTÊMICO DO ADOLESCENTE E SUA FAMÍLIA}

A terapia sistêmica, seja no atendimento familiar ou individual, compreende as pessoas e os problemas por elas referidos de uma forma contextual. Padrões relacionais se interconectam ao longo do tempo numa relação recursiva e complementar. O objetivo não é retirar o sintoma de um ou de outro, mas ampliar a capacidade perceptiva dos sistemas envolvidos acerca dos múltiplos fatores mantenedores do que é referido como queixa ou sintoma (Boscolo \& Bertrando, 2013, Micucci, 2009).

No atendimento psicoterapêutico individual, a pessoa é considerada um sistema humano em interações constantes com outros sistemas. Assim, uma mudança comportamental alcançada no âmbito individual desencadeia mudanças nas relações e rede de interações com os outros sistemas, contemplando assim a ideia de retroalimentação e recursividade (Boscolo \& Bertrando, 2013). 
Uma perspectiva sistêmica de atendimento infantojuvenil envolve considerar os sistemas fundamentais dos quais a criança ou adolescente fazem parte para a compreensão do mundo que os cerca, em especial, a família, a escola e a interação com pares (Guimarães \& Costa, 2003).

Um dos grandes desafios da psicoterapia com pré-adolescentes ou adolescentes é criar um sistema terapêutico tanto para o adolescente quanto para a família, com uma aliança terapêutica que atenda às necessidades de ambos, sem que o terapeuta fique refém de um cabo de guerra. Geralmente, os pais buscam ajuda profissional pela dificuldade de manejo de situações conflituosas que começam a surgir e o adolescente é visto como "culpado" ou aquele que provoca o conflito. O êxito depende do vínculo criado com a família e o adolescente.

Criar uma relação de confiança é fundamental para ativar processos criativos e recursivos entre pais e filhos, com o objetivo de fazer coisas que antes não eram feitas e despertar novos sentidos. Ou seja, busca-se trabalhar cooperativamente para a melhora de suas relações, a partir de uma responsabilização individual e coletiva em prol dos objetivos acordados.

Criar esse ambiente tanto para família quanto para o adolescente ao mesmo tempo não é, porém, tão simples, pois eles têm motivações diferentes e objetivos distintos para o atendimento. $\mathrm{O}$ terapeuta precisa criar uma estratégia de ajuda que contemple os desafios comuns e, também, as especificidades e pontos de conflitos entre pais e filhos. Precisa ser habilidoso na construção desse vínculo e manejo dos conflitos que vão emergindo na medida em que o processo terapêutico acontece (Escudero \& Muñiz de La Peña, 2008).
Para Rosset (2008), o atendimento do adolescente precisa ter o foco de incentivar sua autonomia, ensinar a perceber e sair dos jogos das famílias e ser um sujeito cada vez mais capaz de conscientizar-se e responsabilizar-se pelo seu próprio funcionamento. É importante validar seus sentimentos e encorajar o trabalho de diferenciação, oferecendo um contexto seguro, um ambiente protegido para expressão dos conflitos, segredos, bem como para a ampliação de suas possibilidades de existência.

$\mathrm{O}$ atendimento dos pais deve visar à aceitação da autonomia do adolescente, à privacidade e aos limites, exercendo suas regras com clareza e sem culpa. Ou seja, a família não é um agente externo ao qual o terapeuta se contrapõe, mas sim um sistema fundamental que pode ser potencializado para facilitar e melhorar a saúde do adolescente (Rosset, 2008).

Para o terapeuta, o desafio é poder circular com esses sistemas sem tomar partido de um ou de outro, mas determinando com clareza o espaço do vínculo a ser estabelecido. Fazer-se perguntas sobre sua própria adolescência, estar consciente de seu momento naquela relação terapêutica, buscar orientações e ter uma rede de apoio estão entre as medidas que podem ser tomadas para que esse resultado seja positivo (Carter \& McGoldrick, 1995a).

\section{ESTUDO DE CASO: 0 ATENDIMENTO SISTÊMICO AO ADOLESCENTE E A ORIENTAÇÃO DE PAIS}

Este trabalho tem natureza qualitativa, em formato de estudo de caso clínico. Trata-se de um método de estudo que contribui para a compreensão de fenômenos no decurso de um tempo específico, permitindo entendê-lo 
em maior profundidade, bem como as transformações e desdobramentos associados à psicoterapia (Turato, 2003).

Os nomes utilizados para apresentação do caso são fictícios e os participantes aquiesceram via termo de consentimento livre e esclarecido que as informações e registros do atendimento poderiam ser utilizados para apresentação e produção de textos acadêmicos e científicos, conforme as normas éticas do Código de Ética do profissional psicólogo e da Resolução 466/2012 do Conselho Nacional de Saúde.

Realizou-se o atendimento em psicoterapia sistêmica individual com uma adolescente (Aurora, 11 anos). O recorte temporal para o artigo se refere aos atendimentos realizados em 2017, num total de 38 sessões. Os encontros foram semanais, com duração de 50 minutos. A cada quatro encontros, era prevista uma sessão de orientação de pais, sendo que foi agendado o total de 6 sessões com a participação dos genitores Luciana, 40 anos, e José, 44 anos à época. Os atendimentos foram realizados em consultório particular e durante as sessões foram utilizados instrumentos terapêuticos auxiliares como jogos e atividades manuais.

O presente estudo de caso teve como objetivo apresentar uma das possibilidades da psicoterapia sistêmica individual a partir do atendimento psicoterapêutico de uma pré-adolescente. O recorte feito privilegiou aspectos relacionados à transição para a adolescência e à parentalidade, por se compreender que essa é uma demanda importante de produção de conhecimento sobre os adolescentes e suas famílias.

$\mathrm{O}$ atendimento individual da adolescente foi priorizado por se entender que, sistemicamente, a psicoterapia tem efeito circular e alcança também os demais membros do sis- tema familiar. Os encontros de orientação de pais propiciaram reflexão e aprendizagem sobre educação de filhos, mais do que o treinamento de técnicas específicas sobre como lidar com essa faixa etária.

\section{QUEIXA}

A mãe de Aurora procurou atendimento psicológico para a filha em decorrência do baixo desempenho escolar, isolamento e hostilidade no ambiente familiar. Segundo relatou, a adolescente apresentava episódios de tristeza, choro, irritabilidade, além de redução no engajamento das atividades acadêmicas. A maior preocupação da mãe era com o distanciamento observado em sua relação com a filha, descrita até então como muita próxima. A mãe também estava preocupada com o relacionamento entre a adolescente e o pai, já que ambos passavam a maior parte do tempo juntos e os conflitos eram comuns.

\section{CONTEXTUALIZAÇÃo}

Aurora vivia com os pais e uma irmã de 2 anos. A mãe era farmacêutica e trabalhava numa rede de farmácias. O pai era agrônomo, mas estava desempregado há 2 anos e estudava para aprovação em concurso público. Desde quando Aurora era criança, ele trabalhava em outra cidade, chegando a ficar longe de casa por até 30 dias. A mãe passava a maior parte do tempo envolvida com as demandas domésticas e da educação da filha. Depois que o pai perdeu o emprego, a mãe buscou reinserção no mercado de trabalho e o pai assumiu os cuidados domésticos. A família contava com apoio financeiro da 
avó materna de Aurora, que auxiliava nas despesas com educação, moradia, saúde e lazer.

O relacionamento da família da adolescente com as famílias extensas, tanto a paterna quanto a materna, era conflituoso. A avó materna de Aurora adotava uma comunicação baseada em chantagem e barganhas com ela e a filha, prometendo retirar o auxílio financeiro caso não fosse atendida em suas requisições. A mãe de Aurora tinha conflitos importantes com a família do pai, por considerar que a avó e a mãe dele o tratavam de modo infantilizado, inviabilizando sua autonomia e iniciativa na busca pelos projetos da família.

Devido à extensa jornada diária de trabalho da mãe, o pai de Aurora passava a maior parte do tempo em casa e dividia o tempo entre os estudos e o cuidado das filhas. Enquanto a mais nova estava no berçário ele estudava e auxiliava Aurora na rotina - como tarefas de casa e acompanhamento diário. A mãe assumia as tarefas da educação e do cuidado com as filhas nos momentos em que estava em casa.

\section{O PROCESSO TERAPÊUTICO: CAMINHOS EM CONSTRUÇÃO}

Aurora se definia como uma pessoa alegre, companheira, risonha e que gostava de dançar. Não se queixava da escola e dos relacionamentos que ali mantinha, embora afirmasse que não gostava de estudar. Lamentava-se de uma sobrecarga na vida familiar quando sentia que precisava ser a mediadora para garantir um clima afetivo tranquilo e alegre entre o grupo.

No primeiro encontro de acolhimento, como de costume na prática da terapia com crianças e adolescentes, os pais foram entrevistados. A mãe des- creveu Aurora como alguém que estava se distanciando e de quem ela não conseguia mais se aproximar. Quando perguntada sobre as expectativas em relação ao atendimento da filha ela afirmou, aos prantos, "eu quero a minha filha de volta" (sic). O pai descreveu Aurora como alguém desinteressada, que parecia desafiar ou ignorar sua autoridade e sem muitas preocupações com o futuro. Almejava que o atendimento fosse para a filha o equivalente a um despertar para a vida.

Nessa ocasião, foi realizado o acolhimento, escuta e estabelecimento do contrato terapêutico, incluindo informações sobre duração das sessões, frequência, sigilo e orientação de pais.

No primeiro encontro com Aurora, perguntei para a adolescente: "por qual motivo você acha que seus pais lhe trouxeram aqui?" (sic). A adolescente falou rapidamente que não sabia ao certo, mas que gostava da ideia de ter um espaço para si. Aurora foi convidada a fazer uma autodescrição e um desenho familiar. Ela se descreveu como uma pessoa companheira e amiga, que evitava conflitos, apesar de ter suas próprias opiniões. Parecia desejosa de falar de si e de sua casa, gesticulava com frequência e relatava que sua convivência em casa era tensa, devido às brigas entre seus pais que eram constantes, bem como às dificuldades que todos apresentavam na comunicação.

Ao fazer o desenho da família, Aurora representou graficamente como se percebia, bem como enxergava as pessoas que moravam em sua residência. Referiu-se à mãe com ambiguidade: ora amiga, ora alguém que não a compreendia. Essa contradição também se refletia no modo como tratava sua mãe, com subserviência ou hostilidade, conforme relataram em sessões posteriores. Sobre o pai, referiu que ele era exigente e alguém 
que "emburra rápido". E sobre a irmãzinha, afirmou "ela é mandona".

Por diversas vezes Aurora se definia como a mediadora dos conflitos que aconteciam em casa. Por esse motivo, evitava manifestar suas opiniões e calava-se sempre que era corrigida ou se sentia criticada pelo pai, mãe ou outro membro da família extensa. Relatou que tinha um relacionamento próximo com a avó materna. Mas algumas vezes havia conflitos, pois se Aurora fizesse o que a avó desejava, então ela era recompensada com roupas, acessórios ou outros objetos que lhe interessavam.

$\mathrm{Na}$ escola, relatou que mantinha relacionamentos significativos e duradouros já que convivia com o mesmo grupo desde quando estudava na Educação Infantil. À época da psicoterapia, alguns conflitos entre ela e seus amigos começaram a acontecer, em decorrência de um posicionamento mais assertivo de Aurora sobre divergências nas opiniões e preferências.

Aurora consentiu em participar de encontros terapêuticos semanais e, por meio de uma metáfora, elencamos os objetivos do atendimento. Utilizando a metáfora de um baú há tempos guardado, de onde se retiram objetos não utilizáveis e onde se guardam objetos de valor, sugeriu-se à Aurora que refletisse sobre o que ela desejava para o atendimento. Ela respondeu: "me conhecer e me entender mais e fazer com que meus pais me entendam". Parafraseando, os objetivos do atendimento foram: desenvolver o senso de segurança em si, diferenciar-se dos pais, construir limites para aprender a dizer não, conviver melhor com a família. Daí por diante, os encontros seguintes utilizaram essa metáfora, no sentido de buscar diferenciar entre necessidades dela e necessidades dos pais.
Diversos instrumentos foram organizados para utilização ao longo do atendimento. Dentre eles, o jogo Papo-Cabeça (Costa, 2016) foi útil para disparar as conversas dos primeiros encontros. Com perguntas sobre autoimagem, família, relacionamentos, sentimentos, amigos, autoestima, enfrentamento, esse instrumento facilitou a abordagem à Aurora. As perguntas e respostas eram alternadas entre a terapeuta e a adolescente, de modo que, por meio das respostas, a terapeuta também buscava demonstrar sua disponibilidade para a construção de vínculo e confiança.

À medida que se percebiam aspectos relevantes relacionados aos temas abordados, perguntas eram aprofundadas e a adolescente compartilhava seus interesses, impressões, opiniões, lembranças, medos e sonhos. Como ela se manteve interessada nos temas discutidos, o jogo foi utilizado ao longo de oito sessões. Ao final de cada encontro, a metáfora do baú era retomada com a pergunta: "o que você retira do seu baú hoje e o que você coloca dentro dele?". Nesses momentos, a adolescente refletia, avaliava e considerava suas possibilidades de uma ação diferente da que vinha sendo apresentada na família e no grupo de pares. Esse momento também foi importante porque configurava-se como oportunidade para autoavaliação e avaliação do processo terapêutico em termos de alinhamento dos objetivos e hipóteses levantadas ao início do processo de atendimento.

Terminado o jogo, as sessões seguintes foram para a confecção manual do baú, utilizando revistas e papelão, que, depois de pronto, foi entregue à adolescente como símbolo daquele processo de aprendizagem. Nos encontros em que esse 
objeto foi construído, as conversas foram aprofundadas com perguntas e reflexões sobre o relacionamento com os pais, com a família extensa, com os amigos e sobre relacionamentos amorosos.

Os instrumentos utilizados possibilitaram reflexões sobre hipóteses, emoções e pensamentos relacionados à vivência da adolescente. Nessas conversas, Aurora conseguiu produzir novos sentidos sobre seu sistema parental e sistema fraternal, como o que significava ser a filha mais velha, sobre os sentidos da adolescência, a emergência do primeiro amor, as relações de intimidade e sobre desenvolver o autocuidado. Essas são algumas das principais intervenções do terapeuta sistêmico porque permitem ao próprio paciente mudar concepções, rever emoções e hipóteses sobre suas queixas, como protagonista de sua própria história e desconstruindo um padrão relacional cristalizado em que o profissional detém o saber (Souza, Souza, Rolim, \& Gomes, 2016).

Depois de finalizada essa etapa do atendimento, outro instrumento auxiliar foi o jogo Baralho das Habilidades Sociais (Rodrigues \& Folquitto, 2015). O jogo consiste em cartas com expressões faciais, personagens, situações-problema e objetivos que são utilizados para auxiliar na observação e reflexão sobre os eventos contingentes ao cotidiano dos adolescentes. Foi utilizado com o objetivo de mediar a reflexão sobre a relação de Aurora com seus pares, especialmente no desenvolvimento de um senso de autoeficácia e da habilidade para dizer "não", expressar opiniões, sentimentos, desejos e direitos sempre que sentisse seus limites extrapolados por cobranças no grupo e na família.

\section{O MANEJO CLÍNICO E O CARÁTER TERAPÊUTICO DA ORIENTAÇÃO DE PAIS}

A cada quatro atendimentos com a adolescente foram realizados encontros com os pais, denominados "sessões de orientação de pais". Esses encontros tomaram como referência a leitura de teóricos da área infantojuvenil e familiar (Bowlby, 1989; Kobac \& Mandelbaum, 2003; Walsh, 2016) e de leituras prévias sobre orientação de pais, incluindo cartilhas e modelos de atendimento, bem como a produção teórica e instrumental da autora por ocasião do mestrado em Psicologia Clínica (Macedo \& Conceição, 2015).

Todas as sessões de orientação de pais foram realizadas com a aquiescência e conhecimento prévio da adolescente sobre o que seria abordado. $\mathrm{O}$ sigilo do atendimento individual também era assegurado, de modo que ela compreendeu que essas atividades visavam à sua aproximação com os pais, conforme as queixas referidas.

Criou-se uma ficha autoavaliativa para nortear o levantamento das demandas que foram abordadas com os pais e a reflexão sobre seu relacionamento com a adolescente. Essa ficha surgiu da necessidade de sistematizar $o$ atendimento aos pais, para diferenciá-lo de um processo psicoterapêutico propriamente dito, e, ao mesmo tempo, identificar áreas que serviram como temas-chave e que foram abordadas nas sessões seguintes; serviu como um levantamento de demandas, orientado pelos eixos teóricos: comunicação, afeto e limites, que nortearam todos os encontros de orientação de pais (Macedo, 2017) ${ }^{2}$.

A ficha é um instrumento composto por perguntas sobre aspectos da convivência, diálogo, resolução de conflitos, expressão de sentimentos, 
rotina e distribuição de tarefas, além de perguntas sobre como os pais descrevem a si mesmos no processo educativo e como descrevem os filhos em termos de dificuldades e potencialidades. Trata-se de um instrumento que faz parte de uma produção teórica ainda não publicada por uma das autoras (Macedo, 2017).

Também se buscou criar um clima de acolhimento e esclarecimento de dúvidas sobre o atendimento da adolescente, bem como sobre a reflexão acerca da parentalidade e coparentalidade. As conversas com os pais aconteceram no sentido de propiciar a reflexão sobre seus papéis e a relação do momento atual com suas histórias de vida e família de origem. Tendo em vista que é preciso primeiro engajar os pais, os encontros tiveram o objetivo de acolher suas preocupações, buscar uma aliança que fosse terapêutica também para eles (Escudero \& Muñiz de La Peña, 2008).

Além do preenchimento da ficha autoavaliativa, o primeiro encontro de orientação de pais teve como objetivo diferenciar aspectos da vida conjugal e da relação parental, para, então, propor um esquema de orientação. Eles conseguiram compreender como tais conflitos estavam repercutindo negativamente no relacionamento com a filha adolescente, bem como em seu desenvolvimento. Eles também referiram culpa, dificuldade no ajuste de tarefas entre o pai e mãe na educação da filha e foram encorajados a reconhecer seus acertos e recursos para desenvolver estratégias alternativas àquelas que vinham sendo executadas no processo de educação, como punições e represálias. Foi um momento oportuno para identificar padrões intergeracionais de relacionamento da família de origem e ensaiar novas formas de atuação frente à adolescente.
O primeiro acordo firmado com eles foi uma separação de demandas conjugais e demandas parentais. Os pais de Aurora vivenciavam conflitos importantes, que, sem dúvida, estavam influenciando o relacionamento com a adolescente. Esta, por sua vez, parecia estar caminhando para o lugar de filho parental, assumindo a responsabilidade pela boa convivência entre pai e mãe.

Os demais encontros de orientação de pais tiveram como objetivo dar continuidade às reflexões propostas no acolhimento, bem como levantar demandas que estivessem emergindo do processo terapêutico de Aurora. Os pais descreveram a filha como mais motivada para estudar, responsável e, ao mesmo tempo, mais "respondona", o que para eles significava um maior enfrentamento quando opiniões eram divergentes.

Aqui um parêntese: observou-se que esse termo foi referido pelo pai para descrever as tentativas de enfrentamento que Aurora fazia diante das imposições que, para ela, não eram adequadas, como, por exemplo, as constantes proibições para visitar colegas, vestir certos estilos e roupas ou demonstrar preferências musicais com as quais os pais não concordavam. Entende-se que Aurora estava ensaiando formas diferentes de responder às situações de conflito, pois, costumeiramente, ela se retirava e silenciava, não demonstrando aos pais sentimentos de tristeza, hostilidade e decepção.

Em uma das sessões individuais, a mãe de Aurora foi convidada a participar. Por meio do jogo "Será que conheço você?” (Moura, 2005), realizou-se a mediação de uma conversa entre ambas. O jogo consiste em um conjunto de cartas com perguntas que são respondidas alternadamente pelo filho acerca dos pais e pelos pais acerca do 
filho e o objetivo é emitir o máximo de respostas certas. $\mathrm{O}$ jogo culminou no diálogo sobre tempo, aceitação das diferenças e a adolescente pôde requerer para si a qualidade do relacionamento que queixava ter perdido até então, principalmente após o nascimento da filha mais nova, que ainda demandava cuidado integral. Falou de como se sentia valorizada quando conseguia escuta, diálogo com contato visual e a importância da realização de atividades de lazer na companhia da mãe, como caminhadas e passeios.

No último encontro eles avaliaram os resultados do processo psicoterapêutico com Aurora. O pai relatou que observara uma mudança expressiva no comportamento da filha em relação à mãe. Se antes Aurora ficava em silêncio ou buscava tranquilizar a mãe, agora ela já manifestava quando pensava diferente ou quando se ressentia com os pais. Verbalizava com mais facilidade quando se sentia injustiçada e buscava negociar as regras e limites estabelecidos com os pais por meio de acordos e do diálogo.

\section{RESULTADOS}

O caso de Aurora aqui descrito exemplificou uma das possíveis formas de abordagem à família, no contexto do atendimento psicoterapêutico ao adolescente, a partir dos pressupostos da teoria sistêmica em terapia individual. Uma das vantagens dessa abordagem teórica é que as queixas dos pacientes são vistas como pontos de partida de onde se pode desvelar o potencial construtivo da família (Walsh, 2016).

Nesse estudo, o atendimento individual à adolescente teve o cuidado de não produzir um discurso patológico, a partir de um viés ideológico sobre a crise da adolescência, já trazido pelos pais, outrossim, atuou na direção de ampliar o foco para as demandas e objetivos de mudanças nas relações entre a adolescente e a família, pactuados com a terapeuta.

Por isso, manteve-se o modelo de atendimento individual, combinado com sessões de orientações de pais. As perguntas circularam por meio de diálogos, metáforas, jogos e instrumentos lúdicos que proporcionaram à Aurora a desconstrução e reconstrução de hipóteses de forma recursiva e dinâmica. A cliente referiu como descoberta mais significativa nesse processo o fato de que ela pode e deve iniciar o diálogo com seus pais e seus amigos sempre que se sentir prejudicada ou demandada além de sua capacidade. Em outras palavras, Aurora descobriu sua capacidade de autodeterminação, de produzir diálogos em que há o reconhecimento dela mesma e ao mesmo tempo do outro.

O pai, pessoa de maior valência afetiva para Aurora, referiu que estava conseguindo abordá-la de forma mais assertiva, lembrando-se do exercício diário de enxergá-la como um sujeito singular, com demandas distintas daquelas que ele apresentava, com uma história de vida singular a ser construída. O aspecto da transmissão geracional emergiu, e ele percebeu que seria um fator de risco à saúde mental da filha cristalizar expectativas e conceitos sobre ela, assim como fizera o pai a seu respeito.

Ele também reduziu as altas expectativas em relação a seu desempenho acadêmico, e estabeleceu parâmetros mais realistas, negociados com a adolescente de forma dialogada e democrática. Esse estreitamento de vínculo entre pai e filha foi confirmado pela mãe, que reconheceu os esforços do pai em relação à educação da filha, já 
que ele é quem passava a maior parte do tempo com ela. Por exemplo, em relação ao uso de eletrônicos, ao invés do celular e tablet serem usados como mecanismos de punição e barganha, ele começou a criar regras e parâmetros mais realistas em relação às expectativas sobre seu desempenho escolar, ampliando o tempo e qualidade do diálogo reflexivo sobre os benefícios e prejuízos do uso de eletrônicos. Essa medida reduziu significativamente os conflitos entre pai e filha e possibilitou o início de uma comunicação mais amorosa e tolerante entre eles.

Numa das sessões de orientação, o pai refletiu sobre sua própria adolescência e as repercussões de suas vivências em seu modo de ver os adolescentes, bem como no modo de se relacionar com sua filha. Segundo Escudero \& Muñiz de La Peña (2008), perguntas sobre a adolescência dos pais são importantes para conectá-los ao tempo presente, ajudando-os a serem mais objetivos em relação às expectativas que têm sobre a adolescência dos filhos.

"Eu não quero que aconteça com ela o que aconteceu comigo. Meu pai nunca falou, nunca orientou e se eu tivesse tido o que ela tem, talvez hoje seria diferente." (Pai, 44 anos)

Visto de maneira ecológica, uma mudança de primeira ordem é entendida como uma tentativa visível de algo novo, um comportamento ou ato. A mudança de segunda ordem demanda uma modificação no sistema, como a relação com o filho, o que inclui sua própria relação como filho. O foco deixa de ser o comportamento problemático, por exemplo, para uma compreensão de sua relação com esse filho (Berthoud, 2003). Por exemplo, o pai de Aurora pode perceber como sua concepção de adolescência estaria influenciando seu relacionamento com a filha e como sua própria vivência como filho também impedia uma maior intimidade com ela.

Aurora também observou mudanças no comportamento dos pais. Relatou, ao final das sessões, que se sentia mais feliz porque percebia nos pais a tentativa de dialogar com tolerância e, sobretudo, o real desejo de vinculação com ela. De igual modo, ela mostrou à família o desejo de participar da mudança familiar, a partir da mudança de si mesma. Começou a aceitar as orientações, sobretudo do pai, como tentativas de aproximação e não imposições arbitrárias.

"Assim, eu gosto de conversar com meu pai sobre as coisas, ainda não falo tudo não, mas eu sei que ele fala as coisas pro meu bem." (Aurora, 11 anos)

Essa mudança de paradigma, realizada pela adolescente e estendida aos pais, corrobora a afirmativa de Walsh (2016) sobre a centralidade no potencial cuidador da família. Ao final dessa etapa do processo terapêutico, pai, mãe e filha estavam construindo uma relação alternativa àquela até então existente, mais afetuosa, num clima de pertencimento, aceitação, escuta e diálogo reflexivo.

Em relação ao subsistema conjugal, os pais acolheram o convite de participação em terapia de casal com outro profissional. Inicialmente, a proposta era que, enquanto a adolescente estivesse em psicoterapia individual, os pais poderiam ser acompanhados em suas demandas conjugais, Cogitou-se, oportunamente, ampliar o atendimento para sessões de terapia familiar com todos os membros do grupo, mas o casal optou por suspender o 
atendimento à díade, priorizando a terapia com a adolescente.

No entanto, numa das sessões de orientação de pais, eles relataram que interromperiam a terapia de casal por já alcançarem os resultados esperados em termos de distinguir as funções conjugais e parentais. Nem todos os aspectos relacionados à transmissão geracional, fronteiras entre família nuclear e família extensa foram contemplados, mas, sem dúvida, o casal alcançou mais equilíbrio no desempenho de seus papéis dentro do núcleo familiar.

Esse equilíbrio está entre um dos maiores preditores de saúde mental em um sistema familiar. Segundo Walsh (2016), quando um casal consegue distinguir entre demandas conjugais e parentais, ele demonstra maior disponibilidade para o exercício da função parental. Consequentemente reduz-se de forma significativa os níveis de ansiedade entre os filhos porque eles percebem que não são o "estorvo" dos pais e se sentem confiantes.

Em relação ao subsistema parental, Aurora já não se definia como a responsável pela irmã. Anteriormente ela participava e se envolvia ativamente nos conflitos conjugais quando sua mãe se queixava da rotina familiar; agora já evitava e verbalizava para os pais ao perceber que seus limites eram extrapolados, ou quando era convocada a assumir o lugar parental. Aprendeu a falar como se sentia para seus pais. É importante lembrar que a habilidade de expressar sentimentos está entre uma das mais importantes habilidades para a vida, sugerida pela Organização Mundial de Saúde (WHO, 1997).

"Toda vez que minha mãe começa falar dele ou fico calada ou então eu falo que não posso resolver isso." (Aurora, 11 anos)
Quando sentia falta da presença da mãe, em lugar de se isolar ou recorrer aos pensamentos do tipo "eles não me dão atenção, eles preferem minha irmãzinha, eles estão ocupados demais para mim", já conseguia solicitar momentos de diálogo ou de companhia. De igual modo, depois da última sessão realizada com os três, já conseguia se aproximar do pai e solicitar ajuda, conselhos ou relatar eventos diários da escola. Também referiu ter descoberto que não precisaria mentir para seus pais, pois, afinal, entendera que ela pertencia à família e que eles estavam realmente disponíveis para conviver com ela.

Os pais, por sua vez, estavam mais continentes às demandas de Aurora. A mãe, antes culpada pela extensa jornada de trabalho e cansaço que acabaram a distanciando de sua filha, agora percebia que seus limites não correspondiam à mera falta de vontade, mas sim às condições limitadoras com as quais ela precisou lidar criativamente. Percebeu que, mais do que o tempo físico, a demanda de Aurora era por presença na rotina, com uma participação mais calorosa e menos austera. Ela e a filha concordaram em escolher momentos semanais para ficarem juntas, sem a presença do pai e da filha mais nova.

O pai, inicialmente focado na ideia de controle, da adolescência como uma fase problemática, passou a identificar recursos que ele poderia desenvolver para conhecer melhor Aurora como pessoa, sem o estigma da "aborrescência”. Nos momentos de orientação, pôde revisitar sua adolescência, à qual se referiu, num deles: "eu fui mesmo aborrecido na adolescência e acho que estou nela ainda", como alguém preocupado com possíveis "descaminhos" que a filha pudesse realizar.

Em relação à família extensa da adolescente, os desafios ainda persis- 
tiam após os encontros, já que a avó materna de Aurora, como colaboradora ativa na vida financeira da família, usava de recursos como barganhas e certa permissividade no relacionamento com ela e sua família. Cogita-se a possibilidade de, oportunamente, esse atendimento ser revertido em terapia familiar, quando assim a família demandar.

Como foi visto, o processo terapêutico com Aurora teve efeito circular, beneficiando também o sistema familiar. O pai, que vivia um período de desequilíbrio emocional por não estar à altura da condição de provedor, voltou-se aos recursos do momento para manter uma relação satisfatória com a filha: presença física por dispor de maior tempo em casa. Se o desemprego do pai fosse visto unicamente como um problema a ser resolvido pela família, poderia ter imobilizado o processo de crescimento do grupo em relação ao tempo que eles viviam.

A participação paterna na educação dos filhos é um dos fatores que contribui para o desenvolvimento social humano, incluindo redução da desigualdade de gênero e exercício da coparentalidade. A função do pai na família contemporânea vai além de prover e proteger. Tem-se cada vez mais reconhecida a importância da participação paterna nas atividades educativas diárias, com impacto positivo para a saúde mental das famílias e da sociedade (Beiras \& Souza, 2015; Walsh, 2016).

Essas evidências justificam uma mudança de perspectiva, de um modelo patriarcal para a coparentalidade e para a educação compartilhada entre todos os membros do grupo familiar. Isso mostra que na própria família há recursos para a mudança, em sua diversidade de formatos. Nesse caso, embora desempregado, o pai de Au- rora tinha em seu favor a gestão do próprio tempo, podendo exercitar sua função parental.

A situação da família de Aurora, em vez de estagnar, mobilizou outros recursos desse sistema para o cuidado e proteção uns dos outros. A mãe pareceu estar lidando melhor com sua ausência de casa, reconhecendo sua importante colaboração no sustento familiar, e o pai conscientizou-se de que estaria subutilizado com as tarefas que realizava.

Finalizado esse estágio do atendimento, soube-se que a família havia montado um negócio local para a venda de bolos caseiros, já que o pai apresentou reconhecidas habilidades culinárias. Ou seja, diante de uma situação crítica de desemprego e escassez, novos recursos foram mobilizados e o sistema familiar inteiro se reorganizou para um funcionamento alternativo ao modelo patriarcal.

Aurora também passou a reconhecer como importantes as suas próprias experiências. Tem agora o desafio de buscar sua autonomia, movimentar-se com mais liberdade. Outro ganho desse processo terapêutico foi o reconhecimento de sua própria competência interna. Deixou de se descrever como criança e de sempre buscar a aprovação dos pais em seus comportamentos. Ao final do processo terapêutico, expressava o desejo de vivenciar experiências que são inerentes a essa etapa: saber o que é gostar de alguém, iniciar relacionamentos amorosos, pertencer a um grupo.

Considera-se como ganhos desse atendimento o estabelecimento de fronteiras mais visíveis entre os subsistemas conjugais e parentais, bem como uma maior diferenciação de Aurora, na direção de fazer escolhas mais autônomas e responsáveis, liberada da função de mediar os de-

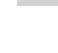


sentendimentos entre seus pais. Em outros contextos, Aurora já consegue manejar melhor a pressão dos pares e se comunicar com assertividade.

\section{CONSIDERAÇÕES FINAIS}

Uma das dificuldades encontradas pelos terapeutas sistêmicos é a escassez de relatos sobre o atendimento individual de crianças e adolescentes. A própria emergência da terapia familiar sistêmica, como uma alternativa aos modelos tradicionais e patologizantes, pode suscitar questionamentos sobre a pertinência do atendimento individual a esses sujeitos, em detrimento de tantas demandas familiares. Caberia então o atendimento individual sistêmico ao adolescente?

Certamente, o atendimento familiar beneficiaria todo o grupo. No entanto, como referido anteriormente, consideramos como desafio e como necessidade construir espaços terapêuticos aos adolescentes, de modo que tanto suas demandas específicas sejam contempladas, como as queixas familiares sejam acolhidas e contextualizadas ao momento do desenvolvimento do ciclo da família.

Somado a isso, a cultura de invisibilidade construída em torno da ideia de adolescência acaba por negligenciar a demanda psicológica que existe nesse estágio. A ideia de que a crise da adolescência é passageira, e, por isso, normal, acaba por empobrecer a prática clínica, muitas vezes, limitada à polarização onde, de um lado pais se queixam e, de outro, adolescentes resistem, ambos sem efetivarem mudanças em seus padrões de comportamento.
Entende-se, portanto, que este estudo pode auxiliar terapeutas infantojuvenis e terapeutas sistêmicos em suas práticas, porque se torna um caminho alternativo às terapias tradicionais com crianças e adolescentes. Em que pese as contribuições das diversas abordagens teóricas na psicoterapia com esses sujeitos, a literatura brasileira ainda é escassa sobre o manejo clínico dessa faixa, utilizando-se como referência a terapia sistêmica.

Constatamos que essa perspectiva é viável no setting individual e contempla também as necessidades da família, no contexto da psicoterapia infantojuvenil. Outra contribuição dessa perspectiva de atendimento é a possibilidade de compreender a adolescência mais próxima de seu contexto, do que a partir de conceitos já formulados sobre as transformações dessa faixa etária. A intervenção não buscou a adaptação da adolescente, mas, recursivamente, ela e os pais foram descobrindo recursos e substituindo arcaicas formas de comunicação pela criação conjunta do espaço relacional entre eles.

Entendemos que a terapia sistêmica individual pode ser um espaço terapêutico para o adolescente, ao mesmo tempo em que amplia o olhar aos sistemas parental e conjugal, mas sem perder de vista a necessidade do atendimento individual. Realizar sessões individuais e sessões de orientações de pais com o foco na dinâmica relacional do grupo familiar e suas ressonâncias no desenvolvimento do adolescente é, pois, possível para a terapia sistêmica individual. 


\section{REFERÊNCIAS}

Andolfi, M. (1984). O indivíduo e a família: dois sistemas em evolução. In M. Andolfi et al. (Orgs.), Por trás da máscara familiar (pp. 17-26). Porto Alegre: Artes Médicas.

Beiras, A. \& Souza, C. D. (2015). Contribuições da participação da figura masculina e da coparentalidade para o desenvolvimento integral da criança na primeira infância. In $G$. A. Pluciennik, M. C. Lazzari, \& M. F. Chicaro (Eds.), Fundamentos da família como promotora do desenvolvimento infantil: parentalidade em foco (pp.58-68). São Paulo: Fundação Maria Cecília Souto Vidigal.

Berthoud, C. M. (2003). Ressignificando a parentalidade: desafios de ser pais na atualidade. São Paulo: Cabral Editora Universitária.

Boscolo, L. \& Bertrando, Pr (2013). Terapia sistêmica individual: manual prático na clínica. Belo Horizonte: Artesã.

Bowlby, J. (1989). Uma base segura: aplicações clínicas da teoria do apego. Porto Alegre: Artes Médicas.

Carter, B. M. \& McGoldrick, M. (1995a). As mudanças no ciclo de vida familiar: uma estrutura para a terapia familiar. In As mudanças no ciclo de vida familiar (2a ed., pp. 7-29). Porto Alegre: Artmed.

Carter, B. M. \& McGoldrick, M. (1995b). Transformação do sistema familiar na adolescência. In As mudanças no ciclo de vida familiar ( $2^{\text {a }}$ ed., pp.223247). Porto Alegre: Artmed.

Costa, M. F. A. A. (2016). Autoconhecimento e coaching para adolescentes e adultos. Foz do Iguaçu, PR: Terapia Criativa.

Cowan, P. A. \& Cowan, C. P. (2016). Transições familiares normativas, qualidade da relação do casal e de- senvolvimento sadio dos filhos. In F. Walsh (Org.), Processos normativos da família: diversidade e complexidade (pp.428-451). Porto Alegre: Artmed.

Diamond, G. S. \& Stern, R. S. (2003). Attachment-based family therapy for depressed adolescents: repairing attachment failures. In V.E. W. Johnson (Org.), Attachment processes in couple and family therapy (pp. 191214). New York: The Guilford Press. Escudero, V. \& Muñiz de La Peña, C. (2008). Adolescentes y familias en conflicto: Un modelo de intervención focalizada en la alianza terapéutica. Sistemas Familiares, 26(1), 61-91. Recuperado de http://www. centroterapiafamiliar.com/wp-content/uploads/2010/03/TFAdolescentes SitFam2010.pdf

Feinberg M. (2003). The internal structure and ecological context of coparenting: A framework for research and intervention. Parenting: Science and Practice, 3, 95-131. Recuperado de http://pepsic.bvsalud.org/ scielo.php?script=sci arttext\&pi$\mathrm{d}=$ S0104-12822005000300010

Guimarães, F. L. \& Costa. L. F. (2003). Clínica psicológica do adolescente: do sistema à abordagem narrativista. Paideia (Ribeirão Preto), 12(24), 163-174.https://dx.doi.org/10.1590/ $\underline{\text { S0103-863X2002000300005 }}$

Kobac, R. \& Mandelbaum, T. (2003). Caring for caregiver: an attachment approach to assessment and treatment of child problems. In V.E. W. Johnson (Org.), Attachment processes in couple and family therapy (pp.144-164). New York: The Guilford Press.

Lopes Oliveira, M. C. (2006). Identidade, narrativa e desenvolvimento na adolescência: uma revisão crítica. Psicologia em Estudo, 11(2), 427- 
436. https://dx.doi.org/10.1590/ S1413-73722006000200022

Macedo, E. O. S. (2010). Significações sobre adolescência e promoção da saúde entre os participantes de um grupo educativo. Dissertação de Mestrado, Programa de Pós-graduação em Psicologia Clínica e Cultura, Universidade de Brasília, DF. Recuperado de http://repositorio.unb.br/ handle/10482/11916

Macedo, E. O. S. (2018). A relação entre família e escola na adolescência: vínculos e afetos como dispositivos de cuidado e proteção. Tese de Doutorado, Programa de Pós-graduação em Psicologia Clínica e Cultura, Universidade Brasília, DF. Recuperado de http://repositorio. unb.br/handle/10482/34320

Macedo, E. O. S. \& Conceição, M. I. G. (2015). Significações sobre adolescência e saúde entre participantes de um grupo educativo de adolescentes. Psicologia: Ciência e Profissão, 35(4), 1059-1073. Recuperado de https://www.redalyc.org/articulo. oa? id=282043249006

Margolin, G., Godis, E. B., \& John, R. S. (2001). Coparenting: a link between marital conflict and parenting in two-parent families. Journal of Family Psychology, 15(1), 3-21. http://dx.doi. org/10.1037/0893-3200.15.1.3

McGoldrick, M. \& Shibusawa, T. (2016). $\mathrm{O}$ ciclo vital familiar. In $\mathrm{F}$. Walsh (Org.), Processos normativos na família (pp.375-398). Porto Alegre: Artmed.

Micuccil, J. A. (2009). The adolescent in family therapy: harnessing the power of relationships. New York: The Guilford Press.

Moura, C. B. (2005). Será que conheço você? Jogo terapêutico para pais e filhos. Foz do Iguaçu, PR: Terapia Criativa.
Nichols, M. P. \& Schwartz, R. C. (2007). Os fundamentos da terapia familiar. In Terapia familiar: conceitos e métodos (pp.21-27). Porto Alegre: Artmed.

Rodrigues, C. L. \& Folquitto, C. T. (2015). Habilidades sociais: desenvolvendo as relações. Novo Hamburgo, RS: Sinopsys.

Rosset, S. M. (2008). Famílias com adolescentes. In L. C. Osório, E. M. Valle ( Orgs.).Manual de terapia familiar (pp. 263-272). Porto Alegre: Artmed.

Souza, C. D., Souza, J. B., Rolim, N. D. 0., \& Gomes, R. C. M. (2016). Intervenções psicológicas com crianças no CRAS: em busca de recursos e potencialidades. Nova Perspectiva Sistêmica, 25(55), 31-45.

Turato, E. R. (2003). Tratado da metodologia de pesquisa clínico-qualitativa: construção teórico-epistemológica, discussão comparada e aplicação nas áreas da saúde e humanas. Petrópolis, RJ: Vozes.

Vasconcelos, M. J. E. (2010). Pensamento sistêmico: o novo paradigma da ciência. Campinas, SP: Papirus.

Walsh, F. (2016). Processos normativos da família: diversidade e complexidade(4a ed.) Porto Alegre: Artmed.

World Health Organization [WHO]. (1997). Programme of mental health. Division of mental health, life skills education in schools. Genebra: Author.

World Health Organization [WHO]. (2014). Health for the world's adolescents: a second chance in the second decade. Recuperado de https://apps.who.int/iris/bitstream/ handle/10665/112750/WHO FWC MCA 14.05 eng.pdf;jsessionid=EA091869043DF35DB653FD52CB9F2E4F? sequence $=1$ 


\section{ETIENE OLIVEIRA SILVA DE MACEDO}

(https://orcid.org/0000-0001-6604-1516)

É psicóloga com Mestrado e Doutorado em Psicologia Clínica e Cultura (UnB). Psicoterapeuta infantojuvenil com formação em Terapia Familiar (IEP-Goiânia). Professora Titular na Universidade Paulista (Campus Goiânia).

E-mail: etienemacedo@gmail.com

\section{ANALICE DE SOUSA ARRUDA VINHAL CARVALHO}

(https://orcid.org/0000-0003-4363-1243) É psicóloga com Mestrado em Family Sciences pela BYA (EUA). Doutorado em Psicologia pela PUC-Goiás. Professora Adjunta na Universidade Paulista (Campus Goiânia) e PUCGoiás. Terapeuta de Casais e Famílias. Professora de Especialização em Terapia de Casais e Famílias.

E-mail: analicearrudavinhal@gmail.com 